\section{Sleep Disorders in Climacteric Women of the Northeastern City of Brazil}

\section{Abstract}

Introduction: One of the stages of women's lives is the climacteric, a period often accompanied by emotional and physical signs and emotional, which may negatively influence the quality of life. Among the typical climacteric symptoms are sleep disorders, often overlooked by professionals who assist the woman.

Objective: Identifying factors related to sleep disorders in cliamcteric women, in the city of Cajazeiras, Paraíba, Brazil.

Method: A cross-sectional survey conducted in the city of Cajazeiras, with 411 women 40-60 years old, belonging to the Family Health Units in the urban area, included in the sample after reading and signing the Informed Consent. Data were collected through interviews with structured questionnaire and analyzed using the Statistical Package for the Social Sciences (SPSS). The exposure variables were: meals/ day, sedentary lifestyle, smoking, alcohol consumption, overweight/ obesity, hypertension and diabetes, which were dichotomized to enable the calculation of the odds ratio $(O R)$ with $\mathrm{Cl} 95 \%$ and $p<0.05$. The research project was approved by the Research Ethics Committee of the State University of Paraíba, Protocol 0462.0.133.000-11.

Results: The average age of the study population was 49.73 ( \pm 5.799 ). The average number of years studied was $7.72( \pm 4.76)$. Regarding per capita income, the average was 0739 ( \pm 0.811$)$. The sleep complaints prevailed in $65.5 \%(n=269)$. By the findings, it was realized that the variables associated with sleep disorders were: alcoholism [ $p$ $=0.014 ;$ OR: 1.845 (Cl 1.085-3.139)]; presence of illnesses $[p=0.004$; $O R$ : $1.796(\mathrm{Cl} 1.185-2.725)]$ and hypertension $[\mathrm{p}=0.005 ; \mathrm{OR}: 1.827$ (Cl 1.164-2.868)].
Maria do Carmo Andrade Duarte de Farias ${ }^{1}$, Fabíola Fialho Furtado², Marilena Maria de Souza ${ }^{3}$, Laurita da Silva Cartaxo ${ }^{3}$, Raimunda Andrade Duarte ${ }^{4}$, Kévia Katiúcia Santos Bezerra', Anne Milane Formiga Bezerra ${ }^{5}$, Aucélia Cristina Soares de Belchior ${ }^{6}$, Paloma Lopes de Asevêdo', Zildeneide Alves de Sá8, Romeryto Coelho Pinto de Almeida9

1 Academic Unit of Life Sciences. Teacher training center, Federal University of Campina Grande. Cajazeiras, Paraíba, Brazil.

2 Federal University of Paraiba. João Pessoa, Paraíba, Brazil.

3 Academic Unit of Nursing. Teacher training center, Federal University of Campina Grande. Cajazeiras, Paraíba, Brazil.

4 Education Department of the municipality of Cajazeiras, Paraíba, Brazil.

5 Nurse in a Mobile Emergency Service, MSU, Sousa, PB, Brazil.

6 Faculty Integrate of Patos, Paraíba, Brazil.

7 Health Department of the municipality of São João do Rio do Peixe, Paraíba, Brazil.

8 Health Department of the municipality of Sousa, Paraíba, Brazil.

9 Student of Nursing of Academic Unit of Nursing. Federal University of Campina Grande. Cajazeiras, Paraíba, Brazil.

\section{Corresponding author:}

Maria do Carmo Andrade Duarte de Farias

झ carmofarias@hotmail.com 
Conclusion: The high prevalence of sleep disorders, the unfavorable socio-demographic conditions and morbid factors found confirm the strong impact of menopause on women's lives. We realize the need to investigate other risk factors for sleep disorders, associated with socio-demographic data and intrinsic factors, regarding climacteric.

Keywords: Sleep deprivation; Climacteric; Risk factors.

\section{Introduction}

Climacteric is defined as a phase of biological evolution of woman, in which case the transition process of the reproductive period for non-reproductive. It derives from the Greek word "Climakter" which means "critical point of human life." Like every transition, can impact a woman's life, marked by hormonal and emotional changes [1].

For some women this phase is lived pathological form with behavioral changes, mood, irritability, insomnia, damaging the quality of life; others, due to the growth, maturity and achieved realization, experience this period in a healthy way, viewing it as an opportunity to build rewarding experiences [1].

Sleep disorders are among the main complaints by women during climacteric, which are overlooked by health professionals. Some studies have reported that sleep difficulties are greatly increased during the period of menopause, and that certain factors contribute to its appearance, highlighting: sociodemographic (age, marital status, education, employment, ease/difficulty to pay for basic needs) psychological (stress, depression, irritability and palpitations), social support (friends, relatives), vasomotor symptoms (hot flushes and sweating), attitudes and unhealthy behaviors (physical inactivity, cigarette smoking, alcoholic beverages and body mass index - BMI inappropriate/high), morbid conditions (diabetes, hypertension, heart disease, osteoporosis, cancer) and low perception of the low self-esteem health [2].

Insomnia is the combination of difficulty initiating or maintaining sleep, causing losses for daily activities such as excessive fatigue, altered performance or emotional changes. The causal factors of insomnia are divided into predisposing, precipitating and perpetuating, which outline the formation of insomnia as a constant process [3].

A transient insomnia, occasional nights up to three weeks, can be closely connected to the surrounding events, psychological overload or sudden change in medical condition. In turn, the predisposing characteristics for insomnia are female, older age, chronic medical illness or psychiatric, lower socioeconomic status, individuals 'hyperactive', low level of education, poor strategies adjustment and obsessive-compulsive nature [3]. Sleep disorders are associated negatively the quality of life, increasing healthcare costs and resulting in poor performance at work; and can trigger mood disorders, anxiety among others [4].

Climacteric we can see a relative neglect related to the epidemiology of sleep, since, especially in Brazil, data on the quality of basic human need are scarce. Thus, given these predisposing factors, in order to conduct this research was anchored in the event that adverse life style and habits harmful to 
health, highlighting smoking and alcohol consumption, which are risk factors for the occurrence of insomnia.

Thus, this study aimed to identifying factors related to sleep disorders in climacteric women, in the city of Cajazeiras, Paraíba, Brazil.

\section{Method}

It is a cross-sectional survey in Cajazeiras, PB, in the months January 2013 to March 2014. This city is a hub city of Paraiba hinterland, where is located the IX Regional Management of Health of the State of Paraíba. The city has a land area of $566 \mathrm{~km}^{2}$ and population estimate of 58.443 inhabitants [5].

The sample was obtained from probability calculations, based on the formula for the finite population, adopting a 95\% confidence interval, significance level of $5 \%$ and sample error of $5 \%$, based on the population of 9966 women aged 35-65 reported in the Department of the Health Unified System Information - DATASUS [6]. By calculation, the sample to be investigated was 385 women. There were interviewed 543 women, of which were excluded: those who were Hormone Replacement Therapy - HRT ( $n=19$ ), Hysterectomized and use of HRT ( $n=01)$, hysterectomy ( $n=19)$, being facts interfere in menstrual flow; aged 35-39 $(n=54)$ and over 60 ( $n=39)$, as before 40 years old climacteric symptoms is virtually absent and after 60 , too, by adapting to the symptoms and no complaints, facts observed in this study. Thus, the final protocol of the sample totaled 411 women. To correlate the sleep disorders with BMI, were excluded underweight ( $n$ $=8$ ), considering the low frequency, which did not allow statistical analysis.

The women in the sample had 40-60 years registered in 14 Family Health Units, the urban area, the municipality agreed to participate after reading and signing the Informed Consent and Informed. For data collection an interview was performed using an instrument structured guidelines, covering items that have identified socio-economic, demographic, health indicators and the complaint referred for sleep.

Interviews were conducted in the health units, taking advantage of the presence of women to carry out the screening test for cervical cancer or any other reason; in addition, to schedule in advance by the Community Health Agents when needed.

The variables analyzed were: age and education in years, per capita family income, color, marital status, occupation, body mass index - BMl (weight/ height ${ }^{2}$ ), presence of comorbidities (self-reported - at least one disease), hypertension and diabetes (confirmed by registration on Hypertension and Diabetes Program - HIPERDIA and the use of specific medications) and sleep disturbance (reported by difficulty falling asleep, frequent nocturnal awakenings, and waking up earlier than planned).

Family income per capita was obtained by the sum total family income divided by the number of family components, by reference to the minimum wage in real, effective at the time of data collection. Schooling was evaluated based on the total number of complete years of formal study. In regard to color (self-reported) was dichotomized into white or non-white and marital situation, with or without a steady partner.

They were not considered sedentary women who refer physical activity at least 3 times a week, lasting at least 30 minutes.

The sleep disturbance variable was obtained by evaluation of the Blatt-Kupperman Menopausal Index. This index evaluates 11 symptoms, of which the complaint relating to sleep is between vasomotor, and is evaluated according to the intensity with scores 4 (light), 8 (moderate) and 12 (sharp) [7]. For purposes of correlation between the variables, this complaint was categorized as absent or present, regardless of the intensity.

The data collection instruments were listed sequentially. The descriptive results were used for 
the mean and standard deviation of the variables age, education and per capita income, and the prevalence of lifestyle variables and morbid frames, based on the total of 411 women interviewed. To investigate the prevalence and association of the presence of sleep disorders and correlated variables we used the Odds Ratio with a confidence interval of $95 \%$ and $p<0.05$. For the analysis and tabulation of the data was used the EXCEL program and the Statistical Package for Social Sciences (SPSS) version 17.

This research is part of a research "Symptoms of menopause: severity and associated factors" which had a project approved by the Ethics Committee of the State University of Paraíba - UEPB, according to the protocol number 0462.0.133.000-11, dated 14/09/2011.

\section{Results}

\section{Socio-demographic characteristics, lifestyle and morbid frame of women investigated}

They interviewed 411 women with an average age of $49.73( \pm 5.799)$ years. The participants of the study period averaged $7.72( \pm 4.76)$ years. As for per capita income, women had an average of 0.739 ( \pm 0.811$)$ minimum wage. When searching on the marital status, $69.6 \%(n=286)$ reported living with a partner. With regard to skin color, 51.1\% ( $n=210$ ) considered themselves white. As for the way of life, highlighted that $73.2 \%(n=301)$ were sedentary and $60.8 \%(n=245)$ had a BMI classified as overweight/obese. $46 \%(n=189)$ mentioned at least the presence of the disease (Table 1).

Table 1. Socio-demographic characteristics, lifestyle and unhealthy frames in climacteric women.

\begin{tabular}{lcc}
\hline Particularities & Total & Results \\
\hline Age $^{1}$ & 411 & $49.73( \pm 5.799)$ \\
\hline Schooling & $7.72( \pm 4.76)$ \\
\hline Per capita income & 411 & $0.739( \pm 0.811)$ \\
\hline Marital status (fixed companion) & 411 & $69.6 \%(n=286)$ \\
\hline Skin color (self-referred) & 411 & $51.1 \%(n=210)$ \\
\hline$<4$ meals/daily & 411 & $47.4 \%(n=195)$ \\
\hline Sedentary lifestyle & 411 & $73.2 \%(n=301)$ \\
\hline Smoking & 411 & $21.2 \%(n=87)$ \\
\hline Alcoholism & 411 & $21.9(n=90)$ \\
\hline Overweight/Obesity ${ }^{2}$ & 411 & $60.8 \%(n=245)$ \\
\hline With illnesses & 403 & $46.0 \%(n=189)$ \\
\hline Presence of SAH & 411 & $33.8 \%(n=139)$ \\
\hline Presence of Diabetes & 411 & $11.2 \%(n=46)$ \\
\hline
\end{tabular}

1: Average (Standard deviation); 2: Deleted 08 cases of low birth weight.

${ }^{*} \mathrm{SAH}$ - Systemic Hypertension

Source: Research data. Cajazeiras, Paraíba, Brazil, 2013-2014. 


\section{Factors related to sleep disor- ders in climacterium}

\section{Lifestyle and the occurrence of sleep disorders in climacteric}

According to the data shown in Table 2, the complaint concerning the sleep prevailed in $65.5 \%$ ( $n=269)$ of 411 climacteric women investigated. Given this high prevalence, we sought to investigate what factors are related to that event. In this sense, there was a correlation between the indicator variables of lifestyle and sleep disorders, revealing that this complaint was associated with the use of alcohol by women with this habit had almost twice the chance of having problems sleep $[p=0.014 ; O R$ : 1.845 (Cl 1.085-3.139)].

Morbid frames and the occurrence of sleep disorders in climacteric

The data shown in Table 3 shows the relationship of morbid frames with the occurrence of changes in sleep patterns in climacteric women. It was noticed that the variables presence of disease $[p=0.004$; OR: $1.796(\mathrm{Cl} 1.185-2.725)]$ and hypertension $[p=$
0.005; OR: 1.827 (Cl 1.164-2.868)] had a relationship with sleep disorders.

\section{Discussions}

\section{Sociodemographic data, life style and morbid frames}

Aside from age, Table 1 findings with regard to marital status and education, corroborate those found in research whose wives attended the climacteric group of the Family Health Unit of Juiz de Fora - MG, Brazil, which were predominantly married with less than eight years of study; however, the average age was 47 years old [8].

Research conducted in southern Brazil also found among women in the period of menopause and postmenopause, aged 40-65 years old, higher prevalence of married. Regarding the level of education, the group was heterogeneous; especially those with incomplete primary school and high school, the family income had a variation of 0.5 to 6 minimum wages [9].

Table 2. Lifestyle indicators and relationship with sleep disturbances in climacteric women $(\mathrm{n}=411)$.

\begin{tabular}{|c|c|c|c|}
\hline \multirow{2}{*}{$\begin{array}{l}\text { Variables of } \\
\text { Life Style }\end{array}$} & \multicolumn{2}{|c|}{ Sleep disturbance } & \multirow[b]{2}{*}{ p; OR (Cl 95\%) } \\
\hline & $\begin{array}{c}(n=262) \\
n\end{array}$ & $\begin{array}{c}65.9 \% \\
\%\end{array}$ & \\
\hline \multicolumn{4}{|l|}{ Meals/daily } \\
\hline Up to 3 times/day & 130 & 48.3 & $0.349 ; 1.108(0.737-1.665)$ \\
\hline \multicolumn{4}{|l|}{ Sedentary lifestyle } \\
\hline Yes & 198 & 73.6 & $0.452 ; 1.056(0.668-1.668)$ \\
\hline \multicolumn{4}{|l|}{ Smoking } \\
\hline Yes & 60 & 22.3 & $0.259 ; 1.223(0.736-2.032)$ \\
\hline \multicolumn{4}{|l|}{ Alcoholism } \\
\hline Yes & 68 & 25.3 & $0.014 ; 1.845(1.085-3.139)$ \\
\hline
\end{tabular}

Source: Research data. Cajazeiras, Paraíba, Brazil, 2013-2014. 
Table 3. Relationship of morbid frames with changes in sleep pattern in climacteric women.

\begin{tabular}{|l|c|c|c|}
\hline \multirow{2}{*}{ Morbid frames } & \multicolumn{2}{|c|}{ Sleep disturbance } & p; OR (Cl 95\%) \\
\cline { 2 - 4 } & $\mathbf{n}$ & $\%$ & $0.151 ; 1.276(0.839-1.941)$ \\
\hline $\begin{array}{l}\text { BMI } \\
\text { Overweight/obesity }\end{array}$ & 167 & 62.8 & $0.004 ; 1.796(1.185-2.725)$ \\
\hline $\begin{array}{l}\text { Any illness } \\
\text { Yes }\end{array}$ & 137 & 50.9 & $0.005 ; 1.827(1.164-2.868)$ \\
\hline $\begin{array}{l}\text { SAH } \\
\text { Yes }\end{array}$ & 103 & 38.3 & \\
\hline $\begin{array}{l}\text { Diabetes } \\
\text { Yes }\end{array}$ & 34 & 12.6 & $0.131 ; 1.567(0.785-3.131)$ \\
\hline
\end{tabular}

*SAH - Systemic Hypertension

Source: Research data. Cajazeiras, Paraíba, Brazil, 2013-2014.

Hall et al. [10] demonstrated that psychosocial factors are related to sleep disorders in perimenopause. They found that low income is associated with sleep problems, highlighting the difficulties falling asleep or waking up several times during the night sooner than planned, or restless sleep.

Overall, the evidence about the socio-economic and educational data of women investigated in this research reveals economic and educational precariousness. Understanding the sociodemographic characteristics of climacteric women is an important tool to know the profile of the same, for the detection of lifestyle related sleep disorders, and other complaints that they can come forward.

In this regard, research in Brazil [11] found no association between climacteric symptoms and age, confirming a paid occupation and marital status. However, women who had a low educational level were not considered white and with per capita income less presented more severe menopausal symptoms, including insomnia, which was the sixth most reported symptom by participants.

In contrast, in the Study of Women's Health Across the Nation (SWAN) Involving 3.045 Caucasian, Afri- can American, Chinese, Japanese, and Hispanic, researchers found an association between climacteric symptoms and age (sent to the menopausal transition) and marital status [4]. The marital bliss was identified as an important factor related to self-reported sleep disorders in women. Married demonstrated lower rates of sleep disturbances, including difficulty falling asleep, nighttime awakenings, early morning awakening, and restless sleep compared to those reported lower marital happiness, being more evident in Caucasian women and to a lesser degree in the african-American women [12].

Regarding the food, it is known that to the knowledge of food standards and the establishment of causal relationships between diet and disease, it is important to an assessment of the quality of the diet of individuals or population groups. The nutritionally appropriate food can act both the prevention and treatment of diseases. In this sense, more and more obvious it becomes the importance of evaluating the eating habits of the population [13].

Healthy lifestyle habits are extremely important to the quality of life and health promotion [14]. In this sense, physical exercises done in two hours or 
more before bedtime allow the body to cool and maintain a state of fatigue that promotes relaxation. However, excessive fatigue, caused by exhausted or stressful job, can make it difficult to fall asleep. A moderately fatigued person usually reaches restful sleep, especially when fatigue is the result of an enjoyable exercise [15].

The risk of chronic disease and mortality from all causes can be reduced by implementing regular physical activity, leading to higher levels of selfconfidence and personal satisfaction, as well as other benefits such as reducing stress, increasing well-being of sensation and decreased depressive symptoms [16].

Other factors also impair the quality of life of women, emphasizing the legal drugs, tobacco and alcoholic beverages. Considering smoking as a risk factor for insomnia, worth noting that smoking causes addiction to nicotine, and that this factor is included in the group of mental and behavioral disorders related to substance use. In addition to causing such a link, tobacco exposes you to about 4.700 toxic substances, 60 of these carcinogenic [17].

\section{Sleep disorders versus lifestyle}

On the prevalence of sleep disorders after menopause, it is known that the difficulty with sleep, in contrast to other climacteric complaints appear to become more intense. However, it has not yet proved a decisive relationship between sleep disturbances and variations of steroids, which can be related to the severity of vasomotor symptoms or to mental disorders, although there is a more intimate association between insomnia and hot flashes [4,18-19].

In a study of 50 women between the age group 45-59 years it was realized that the problems associated with anxiety, depression, attention deficit and insomnia were very uncomfortable and distressing. However, studies are still restricted on the factors that interfere with sleep patterns in postmenopausal women, and its possible consequences on quality of life [20-21].
The findings in Table 2 reveal that a woman who makes use of alcohol has 1.845 of chance to make a complaint concerning sleep during menopause. Thus, the use of alcohol is a risk factor to the occurrence of changes in sleep pattern at this stage of a woman's life.

Ethanol is described as sleep-inducing, by acting on receptors gamma-aminobutyric acid (GABA) and has been used in several studies of the physiology of sleep [22]. However, ethanol promotes relaxation of the muscles of the upper airways, increasing the resistance of the upper airways and can lead to obstructive sleep apnea (OSA). Additionally, intake of alcohol can prolong the duration of apnea, suppress awakenings, increase the frequency of occlusive episodes and worsen the severity of hypoxemia [23-24].

Several epidemiological studies highlight the OSA as the most common form of sleep disorders and are characterized by the total or partial collapse of the upper airway during sleep, making the exchange of gases and disturbing the sleep quality. This condition is closely related to obesity, age and hormonal changes [24]. Postmenopausal women showed four times higher prevalence of moderate OSA; when compared to premenopausal women; these effects were reversed after hormonal therapy [25].

Finally, the use of alcoholic beverages and stimulants may cause the individual overnight, wake up and stay awake for a period partially. There is evidence that stimulants may actually prevent the person fall asleep or even hinder sleep [26].

\section{Sleep disorders versus morbid frames}

Forward to the findings of Table 3, the variables indicative of morbid frames, which were presented, associated with the occurrence of irregularities in sleep, were the presence of at least one disease and hypertension.

Understanding the occurrence of sleep disorders or morbid frames and that this interference and vice versa, is complex, since the causative factors 
are interrelated. In this research, pathology reports were different, namely: chronic noncommunicable diseases (NCDs) - diabetes I and II, hypertension, thyroid disorders, and cancer, among others (data not shown in table). It also, point to high prevalence of overweight/obesity and physical inactivity among the studied (Table 1).

When insomnia occurs there is hypersecretion of the hormone leptin, secreted physiologically while the individual sleeps, which balance the need for intake and energy expenditure, moderating to satiety. With its hypersecretion there is a greater need for intake, especially carbohydrate, which may trigger or exacerbate obesity, noting that obesity predisposes to chronic noncommunicable diseases degenerative, such as diabetes mellitus [27].

Thus, the sleep disorders are significantly associated with different clinical comorbidities, noting that, in addition to advancing age, "other factors can affect the ability to sleep in older adults, such as drugs, drinking alcohol, caffeine (and other xanthine) and nicotine "[28].

Studies report a lower rate of occurrence of ischemic heart disease in premenopausal women than in men. However, the incidence is high after menopause. This fact is probably associated with the reduction of beneficial effect promoted by estrogen, which may be cited control of the lipid profile, blood pressure and cardiac output. Some studies have reported the ability to induce the release of nitric oxide from endothelial cells, thus promoting vasodilation effect [29].

Similar to what occurs with ischemic heart disease in women, in hypertension is observed generally lower incidence rates compared to men of similar ages and these differences may vary with age. It is noted also that after menopause, blood pressure increases in women at even higher levels than in men. This fact is attributed, in part, to estrogen deficiency. However, there seems to be the only one involved in the onset of post-menopausal hypertension [30].
This research sought to identify whether high blood pressure was a risk factor for the occurrence of sleep complaints, although it has been shown that insomnia and short sleep duration are risk causes high blood pressure in middle-aged individuals suffer from depression [31].

In this regard, we assessed the factors associated with high blood pressure, diabetes, insomnia and depression among Brazilian women, 40-65 years and found that insomnia was the most prevalent morbidity, followed by depression, hypertension and diabetes [32].

In the present study we did not observe an association between diabetes and sleep disorders. However, research has shown that sleep disorders are associated with obesity, diabetes, and advanced age visceral adiposity. In recent years, the discovery of new factors that may be triggering of diabetes mellitus, the relationship between changes in glucose metabolism and decrease in sleep have been the objects of research [27].

Hormone replacement therapy alone seems insufficient to improve the quality of sleep. Despite the obvious relationship between menopause and dissatisfaction in the quality of sleep is necessary in-depth analysis on measures of sleep patterns and sleep disorders, as well as characterize the relationship between the symptoms of sleep, vasomotor symptoms, physical health, aging, menopause and emotional consequences [4].

Recognizes the limitations of this research, because sleep disturbances and morbid frames were self-reported by the subjective nature of the outcome studied, necessitating the research to adopt specific tests in the research to favor the accuracy of the findings.

\section{Conclusions}

Climacteric is a stage of life where women can experience a number of complaints, among them 
the psychological and neurological origin, where there is the insomnia, a symptom of multifactorial etiology, causing negative impact on quality of life and health.

From what was shown with this research is essential to pay attention to factors that predispose to sleep disorders in cliamcteric women, suggest necessary changes in lifestyle, preventing illness at this age, as well as prevent and control the emergence of more health damage.

The results of this research can be questioned, since sleep disorders and morbid frames were selfreported. But they raise the possibility that lifestyle and morbid boards are predisposing factors for dissatisfaction with sleep. Therefore, research should be conducted with this population group, using methods to elucidate the facts accurately, like the polysomnography and laboratory tests, assessing metabolic and hormonal rates.

This study is of paramount importance for creating strategies that meet the population of climacteric women, aimed at reducing predisposing factors and, consequently, decreased sleep disturbance index in this population; it will also increase the knowledge of academics and health professionals on the theme, as it considers insufficient the number of works dealing on the subject. Finally, there is the fact that women give little attention to this symptom during climacteric, not looking for qualified professional help and even be overlooked by health professionals in this phase of a woman's life.

\section{References}

1. Leite ES, Oliveira FB, Martins ÁKL, Ramalho KKA, Torquato JA. Perspectives on women climacteric: concepts and impacts on health basic care. R. pesq.: cuid. fundam. Online, 2012 oct dec; 4(4): 2942-52. Doi 10.9789/2175-5361

2. Souza $\mathrm{CL}$, Aldrighi CL, Lorenzi Filho G. Quality of sleep of climacteric women in São Paulo: some significant aspects. Rev Assoc Med Bras 2005; 51(3): 170-6. Doi: http://dx.doi. org/10.1590/S0104-42302005000300019

3. Rowland L. Treaty of neurology. $11^{\text {a }}$ ed. Rio de Janeiro:
Guanabara Koogan; 2007. cap. 145, p. 947- 55.

4. Kravitz HM, Zhao X, Bromberger JT, Gold EB, Hall MH, Matthews $K A$, et al. Sleep disturbance during the menopausal transition in a multi-ethnic community sample of women. Sleep. 2008 Jul; 31(7): 979-90. PMCID: PMC2491500

5. IBGE. Brazilian Institute of Geography and Statistics. IBGE cidades@. Cajazeiras - PB: basic data. Available from: <http:// www.ibge.gov.br/cidadesat/painel/painel.php?codmun= 250370>

6. IBGE. Brazilian Institute of Geography and Statistics. 2010 demographic sense. Rio de Janeiro, Brazil, 2011. ibge.gov.br/ home/presidencia/noticias/imprensa/ppts/0000000402.pdf

7. Wender COM, Freitas F, De Castro JAS, Vanin C. Climacteric. In: Freitas F, Menke CH, Rivoire WA, Passos EP. Routines in gynecology. Porto Alegre: Artmed; 2011. p. 542-60.

8. Oliveira DM, Jesus MCP, Merighi MAB. Climateric and sexuality: the comprehension of this interface by women attended in group. Texto Contexto Enferm, Florianópolis, 2008 JulSet; 17(3): 519-26. Doi: http://dx.doi.org/10.1590/S010407072008000300013

9. Sanches TR, Gomes AB, Lopes VA, Gomes da Costa LRL, Mosca $L N$. Evaluation of the climateric symptoms in postmenopausal women after menopause and use of isolated soy protein. J Health Sci Inst. 2010;28(2): 169-73. Available from: http://www. unip.br/comunicacao/publicacoes/ics/edicoes/2010/02_abr-jun/ V28_n2_2010_p169-174.pdf

10. Hall M, Bromberger J, Matthews K. Socioeconomic status as a correlate of sleep in African-American and Caucasian women. Ann N Y Acad Sci. 1999; 896: 427-30.

11. De Lorenzi DRS, Danelon C, Saciloto B, Padilha Jr. I. Predicting factors of climacteric symptoms. Rev. Bras. Ginecol. Obstet., 2005 jan; 27(1): 7-11. Doi: http://dx.doi.org/10.1590/S010072032005000100004

12. Troxel WM, Buysse DJ, Hall M, Matthews KA. Marital happiness and sleep disturbances in a multi-ethnic sample of middle-aged women. Behav Sleep Med. 2009; 7(1): 2-19. doi: 10.1080/15402000802577736

13. Felippe F, Balestrin L, Silva FM, Schneider AP. Diet quality of individuals exposed or not to a nutrition education program. Rev Nutrição. Campinas, 2011 Nov-Dez; 24(6): 833-44. http:// dx.doi.org/10.1590/S1415-52732011000600004

14. Galvão NAAS, Farias MCS, Azevedo PRM, Vilar MJP, Azevedo GD. Prevalence of mental disorders and assessment of quality of life in the climaterium. Rev Assoc Med Bra, 2007 SeptOct; 53(5): 414-20. Doi: http://dx.doi.org/10.1590/S010442302007000500017

15. Potter PA, Perry AG. Fundamentals of nursing. $5^{\mathrm{a}}$ ed. Rio de Janeiro: Guanabara Koogan S.A; 2004. cap. 41:1065-90.

16. Sousa CA, César CLG, Barros MBA, Carandina L, Goldbaum M, Marchioni DML, et al. Prevalence of leisure-time physical activity and associated factors: a population-based study in São Paulo, Brazil, 2008-2009. Cad. Saúde Pública, Rio de Janeiro, 
2013 Feb; 29(2): 270-82. Doi: http://dx.doi.org/10.1590/S0102$311 \times 2013000200014$

17. Zaitune MPA, Barros MBA, Lima MG, César CLG, Carandina $L$, Goldbaum M, et al. Factors associated with smoking in the elderly: a health survey in São Paulo (ISA-SP). Cad. Saúde Pública, Rio de Janeiro, 2012 Marc; 28(3): 583-95. Doi: http:// dx.doi.org/10.1590/S0102-311X2012000300018

18. Pien GW, Sammel MD, Freeman EW, Lin H, DeBlasis TL. Predictors of Sleep Quality in Women in the Menopausal Transition. Sleep. 2008 Jul; 31(7): 991-9. PMCID: PMC2491505

19. Pedro AO, Pinto-Neto AM, Costa-Paiva LHS, Osis MJD, Hardy EE. Climacteric syndrome: a population-based study in Brazil. Rev. Saúde Pública. 2003;37(6):735-42. Doi: http://dx.doi. org/10.1590/S0034-89102003000600008

20. Valença CN, Germano RM. Women's conceptions about menopause and climateric. Rev RENE. Fortaleza, 2010 Jan-Marc; 11(1):161-71. http://www.revistarene.ufc.br/vol11n1_html_site/ a17v11n1.htm

21. Vigeta SMG. Sleep changes and menopause: a literature review. Cienc Cuid Saúde, 2007 Jul-Set; 6(3): 377-83. Doi: http://dx.doi. org/10.4025/cienccuidsaude.v6i3.4028

22. LU, J.; GRECO, M.A. Sleep circuitry and the hypnotic mechanism of GABAA drugs. J Clin Sleep Med. 2006 Apr 15; 2(2): S19-26. PMID: 17557503

23. Mitler MM, Dawson A, Henriksen SJ, Sobers M, Bloom FE. Bedtime ethanol increases resistance of upper airways and produces sleep apneas in asymptomatic snorers. Alcohol Clin Exp Res. 1988 Dec; 12(6): 801-5. PMID: 3064641

24. Lam JC, Sharma SK, Lam B. Obstructive sleep apnoea: definitions, epidemiology \& natural history. Indian J Med Res. 2010 Feb; 131: 165-70. PMID: 20308741

25. Bixler EO, Vgontzas AN, Lin HM, Ten Have T, Rein J, Vela-Bueno $A$, et al. Prevalence of sleep-disordered breathing in women: effects of gender. Am J Respir Crit Care Med. 2001 Mar; 163(3 Pt 1): 608-13. PMID: 11254512

26. Potter PA, Perry AG. Great treaty of nursing practice. $3^{a}$ ed. São Paulo: editora Santos; 2005. cap. 21:561-73.

27. Cunha $M C B$, Zanetti ML, Hass VJ. Sleep quality in type 2 diabetics, Rev Latino-om Enfermagem. 2008 Oct; 16(5): 850-5. Doi: http://dx.doi.org/10.1590/S0104-11692008000500009

28. Quinhones MS, Gomes MM. Sleep in normal and pathological ageing: clinical and physiopathological aspects. Rev Bras Neurol., 2011; 47 (1): 31-42. Available from: http://files.bvs.br/ upload/S/0101-8469/2011/v47n1/a2021.pdf

29. Mendelsohn ME, Karas RH. The protective effects of estrogen on the cardiovascular system. N Engl J Med. 1999 Jun 10; 340(23): 1801-11. PMID: 10362825

30. Kim JM, Kim TH, Lee HH, Lee SH, Wang T Postmenopausal Hypertension and Sodium Sensitivity. J Menopausal Med. 2014 Apr; 20(1): 1-6. doi: 10.6118/jmm.2014.20.1.1
31. Gangwisch JE, Malaspina D, Posner K, Babiss LA, Heymsfield SB, Turner JB, et al. Insomnia and sleep duration as mediators of the relationship between depression and hypertension incidence. Am J Hypertens. 2010 Jan; 23(1): 62-9. Doi: 10.1038/ ajh.2009.202

32. Machado VSS, Valadares ALR, Costa-Paiva L, Morais SS, PintoNeto AM. Morbidity and associated factors in climacteric women: a population based study in women with 11 or more years of formal education. Rev Bras Ginecol Obstet. 2012; 34(5):215-20. Doi: http://dx.doi.org/10.1590/S0100-72032012000500005

\section{Comment on this article:}

\section{(f) $[$ in $8+S P$}

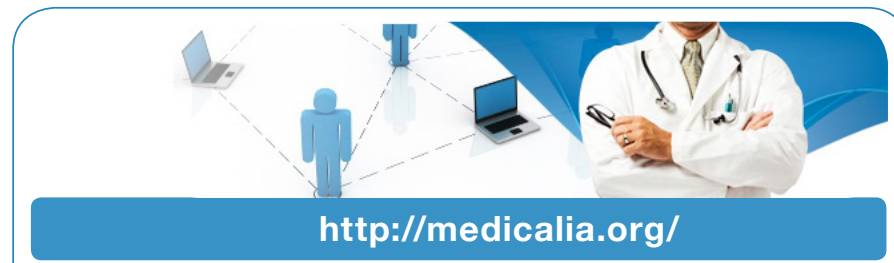

Where Doctors exchange clinical experiences, review their cases and share clinical knowledge. You can also access lots of medical publications for free. Join Now!

Publish with iMedPub

http://www.imed.pub

Neurology and Neuroscience (jneuros.com) is a hybrid, peerreviewed journal that considers articles concerned with any aspect of clinical neurosciences such as neurology, psychiatry and neurosurgery, as well as basic research on neuroscience where neurologists and neuroscientists publish together. 